\title{
Polysaccharide from Angelica sinensis attenuates SNP-induced apoptosis in osteoarthritis chondrocytes by inducing autophagy via the ERK $1 / 2$ pathway
}

Chao $\mathrm{Xu}^{1+}$, Su Ni ${ }^{2+}$, Chao Zhuang ${ }^{3}$, Chenkai $\mathrm{Li}^{2}$, Gongyin Zhao ${ }^{3}$, Shijie Jiang ${ }^{3}$, Liangliang Wang ${ }^{3}$, Ruixia Zhu ${ }^{3}$, Andre J. van Wijnen ${ }^{4^{*}}$ and Yuji Wang ${ }^{3,4,5^{*}}$ (i)

\begin{abstract}
Objective: Chondrocyte apoptosis plays a vital role in osteoarthritis (OA) progression. Angelica sinensis polysaccharide (ASP), a traditional Chinese medicine, possesses anti-inflammatory and anti-apoptotic properties in chondrocytes. This study aimed to determine the protective role of ASP on sodium nitroprusside (SNP)-induced chondrocyte apoptosis, and explore the underlying mechanism.

Method: Human primary chondrocytes isolated from the articular cartilage of OA patients were treated with SNP alone or in combination with different doses of ASP. Cell viability and apoptosis were assessed, and apoptosisrelated proteins including BCl-2 and Bax were detected. Autophagy levels were evaluated by light chain 3 (LC3) II immunofluorescence staining, mRFP-GFP-LC3 fluorescence localization, and western blot (LC3II, p62, Beclin-1, Atg5). Meanwhile, activation of the ERK 1/2 pathway was determined by western blot. The autophagy inhibitors, 3methyladenine (3-MA), chloroquine (CQ), and a specific inhibitor of ERK1/2, SCH772984, were used to confirm the autophagic effect of ASP.

Results: The results showed that SNP-induced chondrocyte apoptosis was significantly rescued by ASP, whereas ASP alone promoted chondrocyte proliferation. The anti-apoptotic effect of ASP was related to the enhanced autophagy and depended on the activation of the ERK1/2 pathway.

Conclusion: ASP markedly rescued SNP-induced apoptosis by activating ERK1/2-dependent autophagy in chondrocytes, and it made ASP as a potential therapeutic supplementation for OA treatment.
\end{abstract}

Keywords: Angelica sinensis polysaccharide, Autophagy, Chondrocytes, Osteoarthritis

\footnotetext{
* Correspondence: vanwijnen.andre@mayo.edu; yujiwang@sohu.com

${ }^{+} \mathrm{Chao} \mathrm{Xu}$ and Su Ni contributed equally to this work.

${ }^{4}$ Department of Orthopedic Surgery and Biochemistry \& Molecular Biology,

Mayo Clinic, Rochester, MN, USA

${ }^{3}$ Department of Orthopedics, The Affiliated Changzhou No.2 People's

Hospital of Nanjing Medical University, 29 Xinglong Alley, Changzhou

213003, China

Full list of author information is available at the end of the article
}

(c) The Author(s). 2021 Open Access This article is licensed under a Creative Commons Attribution 4.0 International License, which permits use, sharing, adaptation, distribution and reproduction in any medium or format, as long as you give appropriate credit to the original author(s) and the source, provide a link to the Creative Commons licence, and indicate if changes were made. The images or other third party material in this article are included in the article's Creative Commons licence, unless indicated otherwise in a credit line to the material. If material is not included in the article's Creative Commons licence and your intended use is not permitted by statutory regulation or exceeds the permitted use, you will need to obtain permission directly from the copyright holder. To view a copy of this licence, visit http://creativecommons.org/licenses/by/4.0/ The Creative Commons Public Domain Dedication waiver (http://creativecommons.org/publicdomain/zero/1.0/) applies to the data made available in this article, unless otherwise stated in a credit line to the data. 


\section{Introduction}

Osteoarthritis, a progressive and degenerative disease, is characterized by degeneration of the articular cartilage and osteophyte formation. Clinical manifestations include joint pain, swelling, joint deformity and, limited movement [1]. Many factors, including age, excessive weight bearing, oxidative stress, physiology, and biomechanical environment changes in joints, can result in OA [2]. Degeneration of the cartilage in OA is mainly due to the dramatically decreased self-repair ability of chondrocytes in a pathological status, presenting as low chondrocyte vitality, abnormally high apoptosis, and eventually loss of homeostasis of chondrocyte metabolism [3].

Many studies have reported that various factors could cause chondrocyte apoptosis, such as inflammation, oxidative stress, and mechanical stress [4, 5]. Growing evidence highlights that oxidative stress in chondrocytes is related to metabolic disorder and mitochondrial damage, which leads to massive apoptosis of chondrocytes. A previous study demonstrated that the nitrite levels, a stable end product of nitric oxide (NO) metabolism, are elevated in the serum and cartilage in OA samples. SNP, a NO donor compound, induces chondrocyte apoptosis via mitochondrial-dependent signaling [6].

Angelica sinensis polysaccharide (ASP), which is extracted with water as the initial extraction solvent, consists of $x y-$ lose, galactose, glucose, arabinose, rhamnose, fructose, and glucuronic acid [7-9]. Some studies have reported that ASP exhibits gastrointestinal protective effects, immunomodulatory effects [10], antitumor activity [11, 12], and anti-inflammatory activity [13]. Furthermore, one study has shown the capacity of ASP to protect chondrocytes from $\mathrm{H}_{2} \mathrm{O}_{2}$-induced apoptosis via its antioxidant effects [14]. However, the influence of ASP on autophagy is unclear.

Autophagy, literally meaning "self-eating", is an intracellular catabolic process of delivering cytosol and/or its specific contents to the lysosomes for degradation. The macromolecular constituents are then recycled and utilized by the cells [15]. Basal level autophagy plays an important role in cellular homeostasis through the elimination of damaged organelles and aggregated intracellular proteins [16]. On the other hand, during conditions of cellular stress, such as nutrient deprivation/ starvation, hypoxia, pathogen infection, radiation, or anticancer drug treatment, the level of autophagy is augmented, resulting in adaptation and cell survival (cytoprotective response) [17]. Once this physiological augmentation of autophagy flux is genetically or chemically blocked, whether during the formation of autophagosome, the fusion of autophagosome and lysosome, or the degradation of autolysosome, cell death will generally increase under stress conditions [18, 19]. Cartilage degeneration and cell death caused by autophagy inhibition play a crucial role in the process of OA [20].

Additional evidence has shown that signaling pathway malfunctions in chondrocytes are involved in agingrelated joint diseases such as OA. Extracellular signalregulated kinase1/2 (ERK1/2) is related to chondrocyte apoptosis, as reported by Shakibaei et al. [21]. However, it was not clear whether there was a relationship between the ERK1/2 signal pathway and autophagy in chondrocytes after treating with ASP and SNP. Thus, our study aimed to identify if there is a link between ASP and autophagy on SNP-stimulated OA chondrocytes in vitro and which signal pathway is involved in it.

\section{Materials and methods Reagents}

ASP was purchased from Shanghai Yilin Biotech. Co., Ltd. (Shanghai, China). The purity of ASP is approximately $92 \%$. The component sugars are glucose, galactose, arabinose, rhamnose, mannose, and xylose. The average molecular weight of ASP is $85.0 \mathrm{kDa}$. ASP was dissolved in PBS and diluted with DMEM-F12 for the experiments. Collagenase II (Worthington Biochemical Corp., Lakewood, NJ, USA) was dissolved in DMEM at $2.5 \mathrm{mg} / \mathrm{ml}$ to digest the articular cartilage. Sodium nitroprusside (SNP) was purchased from Dandong Medical and Pharmaceutical Co., Ltd. (Heilongjiang, China), reconstituted in sterile normal saline at $40 \mathrm{mg} / \mathrm{ml}$, and stored at $4{ }^{\circ} \mathrm{C}$ avoiding light. CQ, 3-MA, P276-00, and SCH772984 were purchased from Selleckchem (Houston, TX, USA).

\section{Isolation and culture of osteoarthritis articular chondrocyte}

Cartilage tissue specimens were obtained from OA patients during joint replacement surgery in the Affiliated Changzhou No.2 People's Hospital of Nanjing Medical University. All participants had signed a written informed consent prior to the subjects entering the study. In addition, the study was approved by the Nanjing Medical University Review Board. The information of subjects was performed in Table 1 . All the tissues were carefully minced and digested with $2.5 \mathrm{mg} / \mathrm{ml}$ collagenase II in serum-free Dulbecco's modified Eagle's medium (DMEM) (Gibco BRL, Grand Island, NY, USA) for $4-6 \mathrm{~h}$ at $37^{\circ} \mathrm{C}$, filtered through a $70-\mu \mathrm{m}$ cell strainer (BD, Durham, NC, USA), extensively washed with blank DMEM/F12, and finally cultured in DMEM/F12 supplemented with $10 \%$ fetal bovine serum (Gibco BRL, Grand Island, NY, USA), $50 \mu \mathrm{g} / \mathrm{ml}$ of ascorbic acid (AA, Sigma), $100 \mathrm{U}$ penicillin, and $100 \mu \mathrm{g} / \mathrm{ml}$ streptomycin (which was referred as the full culture medium for chondrocytes) in a standard cell culture chamber containing $5 \% \mathrm{CO}_{2}$. 
Table 1 Characteristic of subjects investigated

\begin{tabular}{ll}
\hline Characteristics & OA \\
\hline Total number of subjects & 16 \\
Age $^{\text {a }}$, years & 67.4 \\
25th percentile & 64 \\
75th percentile & 72 \\
Number of female/male subjects & $11 / 5$ \\
Disease duration ${ }^{\text {a }}$, years & 5.7 \\
25th percentile & 3 \\
75th percentile & 8 \\
ICRS grade & a \\
25th percentile & 2.8 \\
75th percentile & 2 \\
a $^{\text {Median }}$ & 3 \\
\hline
\end{tabular}

Non-adherent cells were removed after 3 days. Adherent cells were split at a ratio of 1:2 until $90 \%$ confluence. Chondrocytes were used from passages 2 to 3 in subsequent experiments.

\section{Determination of cell viability and proliferation by MTS assay}

Cell viability and proliferation assays were performed using the tetrazolium compound-based CellTiter $96^{\circ}$ AQueous One Solution Cell Proliferation (MTS) assay (Promega, Madison, WI, USA). OA chondrocytes were seeded at approximately 5000 cells per well in 96-well plates in triplicate for 7 days under regular growth conditions (DMEM/F12 with 10\% FBS). After seeding for $24 \mathrm{~h}$, ASP was added into the media, and then the MTS assay was performed daily according to the manufacturer's instructions for the subsequent 6 days. Generally speaking, $20 \mu \mathrm{l}$ of MTS solution reagent was pipetted into each well of the 96-well assay plate containing the chondrocytes in $100 \mu \mathrm{l}$ of fresh culture medium. Then, the plate was incubated at $37^{\circ} \mathrm{C}$ for $2 \mathrm{~h}$ in a humidified, $5 \% \mathrm{CO}_{2}$ atmosphere, and the absorbance at $490 \mathrm{~nm}$ was recorded using an absorbance microplate reader (Elx808 ${ }^{\text {th }}$ Bio-Tek Instruments, Winooski, VT).

\section{Edu cell proliferation assay}

Chondrocytes were seeded in 24-well plates and treated with ASP and P276-00, and then cell proliferation rate was detected by the Yefluor 594 Edu Imaging Kits (Yeasen Co., Ltd., Shanghai, China) according to the manufacturer's instructions.

\section{Cell apoptosis detection by DAPI staining}

Chondrocytes were seeded on sterile glass slides coated with gelatin in a medium without AA and then treated with SNP alone or with ASP for an indicated time. Cells were fixed, and the nuclei were stained with DAPI
(Sigma-Aldrich, MO, USA) in the dark for $5 \mathrm{~min}$, and the fluorescence (Nikon Eclipse Ti, Japan) was observed.

\section{Detection of cell apoptosis rate by flow cytometry: Annexin V/PI staining}

$2 \times 10^{5}$ chondrocytes were seeded in 6-well plates in a medium without AA. Cell apoptosis rates were detected by the Annexin V-FITC/PI kit (Vazyme Biotech Co., Ltd., Nanjing, China) according to the manufacturer's instructions. Generally speaking, the cells were washed with ice-cold PBS and trypsinized. Removing the supernatant after centrifugation, the cells were resuspended in $100 \mu \mathrm{l}$ binding buffer and incubated with $5 \mu \mathrm{l}$ Annexin V-FITC for $10 \mathrm{~min}$ at room temperature avoiding direct light. Then, $5 \mu \mathrm{l} \mathrm{PI}$ and $400 \mu \mathrm{l}$ binding buffer were mixed into the flow tube.

The apoptosis ratio was assessed with a flow cytometer (BD, Biosciences, San Jose, CA, USA), and the results were analyzed and assembled by the FlowJo software (Tree Star, Inc., USA).

\section{Immunofluorescence}

$2-5 \times 10^{4}$ chondrocytes were seeded on sterile glass slides precoated with gelatin in a medium without AA. After the indicated treatment, cells were fixed in $4 \%$ paraformaldehyde at $4{ }^{\circ} \mathrm{C}$ for $15 \mathrm{~min}$ and blocked with PBS containing 5\% normal goat serum and $0.3 \%$ Triton $\mathrm{X}-100$ for $1 \mathrm{~h}$ at room temperature. Staining of the treated cells with LC3A/B (D3U4C) $\mathrm{XP}^{\circ}$ Rabbit mAb (Alexa Fluor ${ }^{\circ} 488$ Conjugate, CST, USA) at 1/100 dilution was performed overnight at $4{ }^{\circ} \mathrm{C}$ in PBS containing $1 \%$ BSA and $0.3 \%$ Triton X-100. The nuclei were counterstained with DAPI in the dark for $5 \mathrm{~min}$, and the fluorescence (Nikon Eclipse Ti, Japan) was observed.

\section{Western blot analysis}

Cultured chondrocytes were lysed with RIPA buffer and boiled. SDS-polyacrylamide gel electrophoresis was conducted on a polyacrylamide gel and transferred to a polyvinylidene fluoride (PVDF) membrane. All antibodies, purchased from Cell Signaling Technology were used to detect the autophagy levels, apoptosis, proliferation, and signaling pathways. Rabbit anti-human $\beta$-actin polyclonal antibody was used to detect the actin signal as an internal control, and relative expression levels were quantified by running the Quantity One software. Antibodies information was performed in Table 2 .

\section{mRFP-GFP-LC3 analysis}

Chondrocytes were seeded in gelatin-precoated slides with a density of $5 \times 10^{4}$ cells. One day after seeding, cells were infected with mRFP-GFP-LC3-labeled adenovirus (Genechem, Shanghai, China) according to the manufacturer's instructions. The virus expresses the 
Table 2 Lists of antibodies

\begin{tabular}{|c|c|c|c|}
\hline Antibodies & Manufacturer & Isotypes & Catalog \\
\hline Atg5 antibody & CST & Rabbit lgG & $\# 2775$ \\
\hline Bax rabbit $\mathrm{mAb}$ & CST & Rabbit lgG & \#5023 \\
\hline Beclin-1 rabbit mAb & CST & Rabbit lgG & \#3495 \\
\hline $\mathrm{BCl}-2$ antibody & CST & Rabbit lgG & \#4223 \\
\hline CyclinD1 rabbit mAb & CST & Rabbit lgG & \#2978 \\
\hline p21 rabbit mAb & CST & Rabbit lgG & \#2947 \\
\hline Phospho-p44/42MAPK(ERK1/2) rabbit mAb & CST & Rabbit lgG & \#4377 \\
\hline P62 antibody & CST & Rabbit lgG & \#5114 \\
\hline ERK1/2 rabbit mAb & CST & Rabbit lgG & \#4695 \\
\hline Ras antibody & CST & Rabbit lgG & \#3965 \\
\hline Raf antibody & CST & Rabbit lgG & \#9422 \\
\hline $\mathrm{p}-\mathrm{MEK} 1 / 2$ rabbit mAb & CST & Rabbit lgG & \#9154 \\
\hline MEK1/2 mouse mAb & CST & Mouse lgG & \#4694 \\
\hline LC3B antibody & CST & Rabbit lgG & \#2775 \\
\hline$\beta$-Actin rabbit mAb & CST & Rabbit lgG & \#4097 \\
\hline
\end{tabular}

monomeric RFP-GFP-tagged LC3 (tfLC3) as an autophagic flux reporter comprised of LC3 protein fused with monomeric red fluorescent protein (mRFP) and green fluorescent protein (GFP). The GFP signal would be quenched within the lysosome lumen by the acidic and/ or proteolytic environment. Yellow puncta which is consist of colocalized GFP (green) and mRFP (red) fluorescent signals in the cytoplasm indicate early autophagosomes, while the mRFP signals alone (red) represent late autolysosomes.

\section{Statistical analysis}

Statistical analyses were performed using Prism (GraphPad Software, San Diego, CA, US). Unpaired Student's $t$ test was used for two groups and one-way ANOVA for more than two groups. The symbols *,**,***, and ${ }^{\#}$ indicated $p<0.05, p<0.01, p<0.001$, and $p<0.0001$, respectively. All quoted $p$ values were 2 -tailed, and those less than 0.05 were considered statistically significant. All data are from $n=3$ biological replicates.

\section{Results}

\section{SNP dramatically attenuates chondrocyte viability} whereas ASP rescues it

In order to determine the best dosage and time period of SNP application, OA chondrocytes were incubated with three different concentrations of $\operatorname{SNP}(0.5,1,2 \mathrm{mg} /$ $\mathrm{ml}$ ) for three different times, and sterile normal saline was added as a control. As demonstrated in Fig. 1a-c, the cell viability of chondrocytes was decreased in a dose-dependent manner. Especially when chondrocytes were treated with $1 \mathrm{mg} / \mathrm{ml} \mathrm{SNP}$, cell viability was reduced by approximately $50 \% \quad(p<0.01)$ after $12 \mathrm{~h}$.
Statistically significant differences in cell viability $(12 \mathrm{~h}$, $24 \mathrm{~h}$, and $48 \mathrm{~h}$ ) were not observed between the $1 \mathrm{mg} / \mathrm{ml}$ and $2 \mathrm{mg} / \mathrm{ml}$ groups $(p>0.05)$ but existed between the 0.5 and $1 \mathrm{mg} / \mathrm{ml}$ groups $(p<0.001)$. Therefore, $1 \mathrm{mg} / \mathrm{ml}$ SNP was used to induce apoptosis for the following studies.

In order to evaluate the protective role of ASP, chondrocytes were pretreated with $50 \mu \mathrm{g} / \mathrm{ml}$ or $200 \mu \mathrm{g} / \mathrm{ml}$ ASP for $2 \mathrm{~h}$ before $24 \mathrm{~h}$ incubation with $1 \mathrm{mg} / \mathrm{ml} \mathrm{SNP}$. Both concentrations of ASP, 50 and $200 \mu \mathrm{g} / \mathrm{ml}$, remarkably rescued SNP-induced damage (approximately 30\%, $p<0.001)$ as Fig. 1d showed, which suggested that ASP may protect chondrocytes from SNP-induced apoptosis.

\section{ASP promotes chondrocyte proliferation in a p21 and CyclinD1-dependent manner}

To explore the effect of ASP on chondrocyte proliferation, we incubated chondrocytes with $200 \mu \mathrm{g} / \mathrm{ml}$ ASP for 6 days (ASP was added daily). The results showed that chondrocytes significantly increased from day 3 to day 6 compared to PBS control (Fig. 2a). To further examine if ASP-induced chondrocyte proliferation depends on the expression of p21 and cell cycle-related protein (CyclinD1), western blot analysis was conducted on day 4. As shown in Fig. 2b-d, ASP significantly decreased p21 $(p<0.0001)$ and increased CyclinD1 $(p<0.0001)$ protein levels. Additionally, P276-00, a CDK4/CyclinD1specific inhibitor, was applied in combination with ASP for 6 days; the MTS results showed that ASP-induced chondrocyte proliferation was abolished when CyclinD1 was inhibited (Fig. 2e). Furthermore, we also used Edu assay to detect chondrocyte proliferation rate on day 4; the results showed the proliferation rate of chondrocytes 
(a)

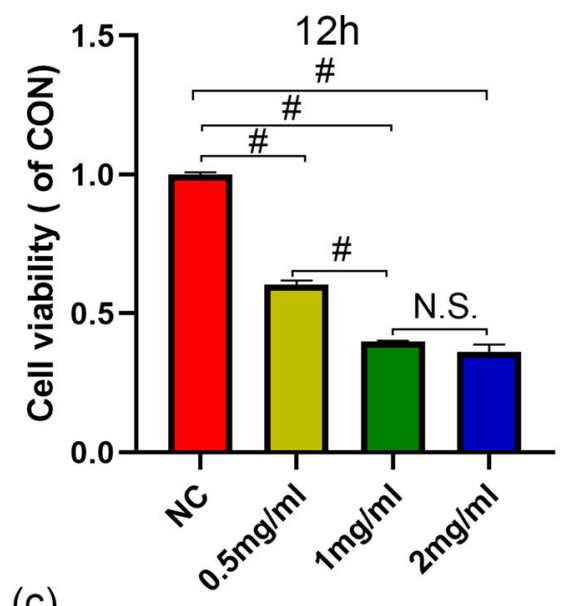

(c)

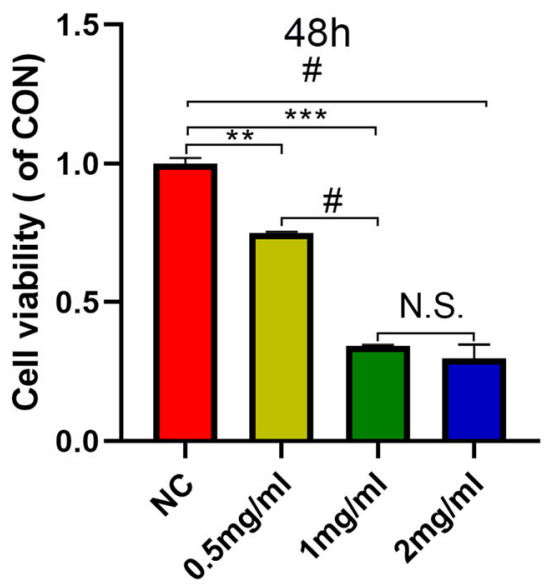

(b)

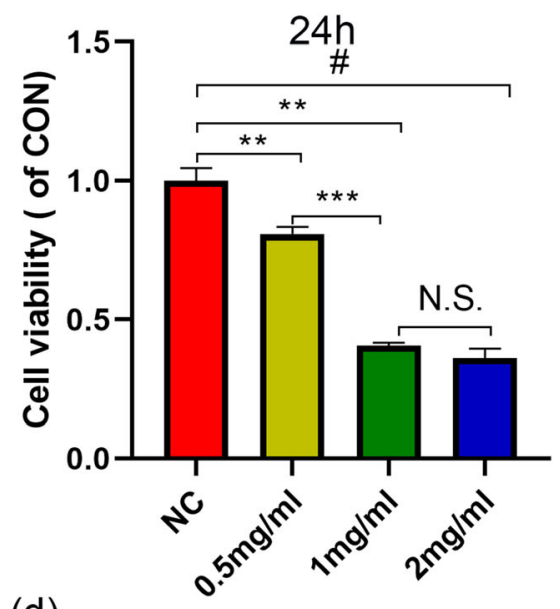

(d)

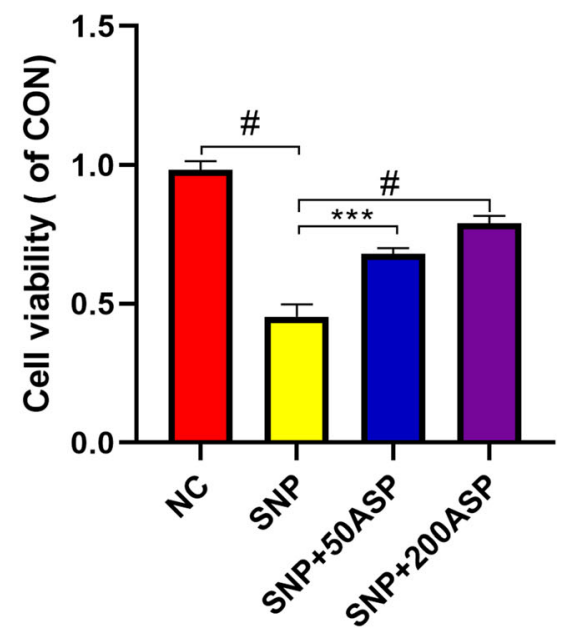

Fig. 1 SNP treatment resulted in a reduction of chondrocyte viability compared with the control group in a dose-dependent manner. a-c OA chondrocytes were cultured with various concentration of SNP $(0.5 \mathrm{mg} / \mathrm{ml}, 1 \mathrm{mg} / \mathrm{ml}$, or $2 \mathrm{mg} / \mathrm{ml})$ for $12 \mathrm{~h}, 24 \mathrm{~h}$, and $48 \mathrm{~h}$. d OA chondrocytes were pretreated with different concentrations of ASP $(50 \mu \mathrm{g} / \mathrm{ml}$ or $200 \mu \mathrm{g} / \mathrm{ml})$, then incubated with SNP for $24 \mathrm{~h}$. Cell viability was analyzed with MTS. The results were presented as the mean \pm SD of three independent experiments $(n=3) .{ }^{* *} p<0.01,{ }^{* * *} p<0.001,{ }^{\#} p<0.0001$, and statistical significance was determined by one-way ANOVA

in ASP-treated groups was increased by about $50 \%$ compared with the control groups. Meanwhile, P276-00 significantly inhibited the chondrocyte proliferation rate (Fig. 2f, g). Collectively, these data suggest that ASP enhances the proliferation of chondrocytes in a p21- and CyclinD1-dependent manner.

\section{ASP protects chondrocytes by inhibiting SNP-induced apoptosis}

To study whether the protective effect of ASP on SNPinduced cytotoxicity was mediated by the apoptotic process, we used DAPI staining and flow cytometry assays to assess chondrocyte apoptosis. Chondrocytes were pretreated with $50 \mu \mathrm{g} / \mathrm{ml}$ or $200 \mu \mathrm{g} / \mathrm{ml} \mathrm{ASP} \mathrm{for} 4 \mathrm{~h}$ and then treated with or without $1 \mathrm{mg} / \mathrm{ml} \mathrm{SNP}$ for $24 \mathrm{~h}$. For the negative control groups, the cells were treated with SNP only. As we expected, SNP significantly increased the percentage of apoptotic chondrocytes compared to the control groups; on the contrary, pretreatment with ASP significantly reduced the percentage of apoptotic chondrocytes (Fig. 3a, c). The DAPI staining results, which intuitively displayed the percentage of apoptotic cells, were consistent with flow cytometry assays (Fig. 3b, d). The balance of anti-apoptotic protein $\mathrm{Bcl}-2$ and proapoptotic protein Bax plays an important role in the regulation of mitochondrial integrity and cell survival. To verify whether the mitochondrial-dependent apoptotic pathway was affected by ASP in chondrocytes, the expression levels of $\mathrm{Bcl}-2$ and Bax were detected. Western blot analysis revealed that SNP significantly 
(a)

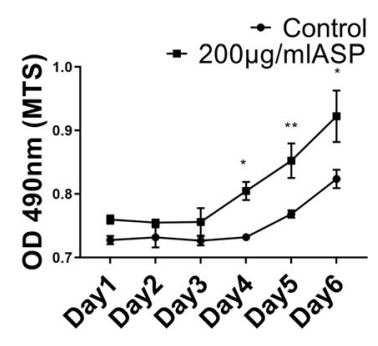

(d)

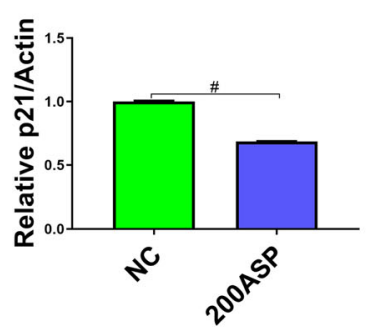

(g) (b)

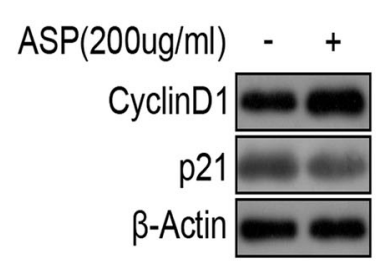

(e)

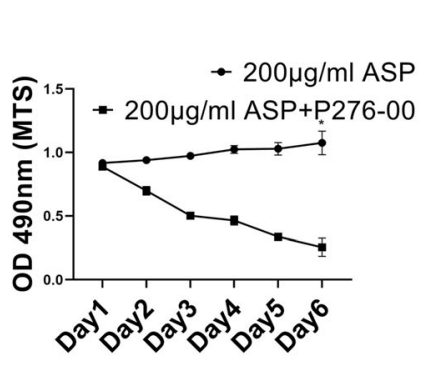

(c)

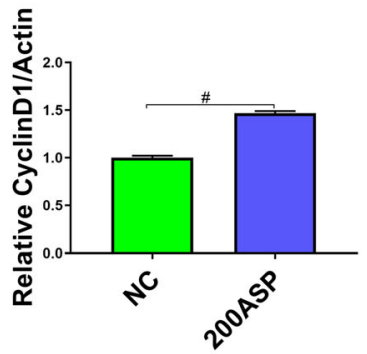

(f)

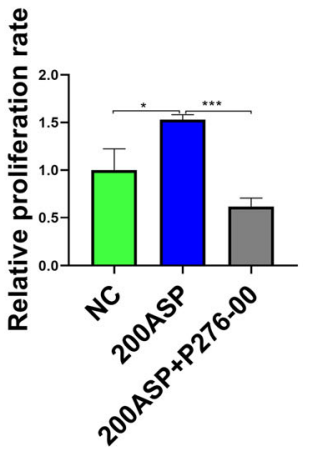

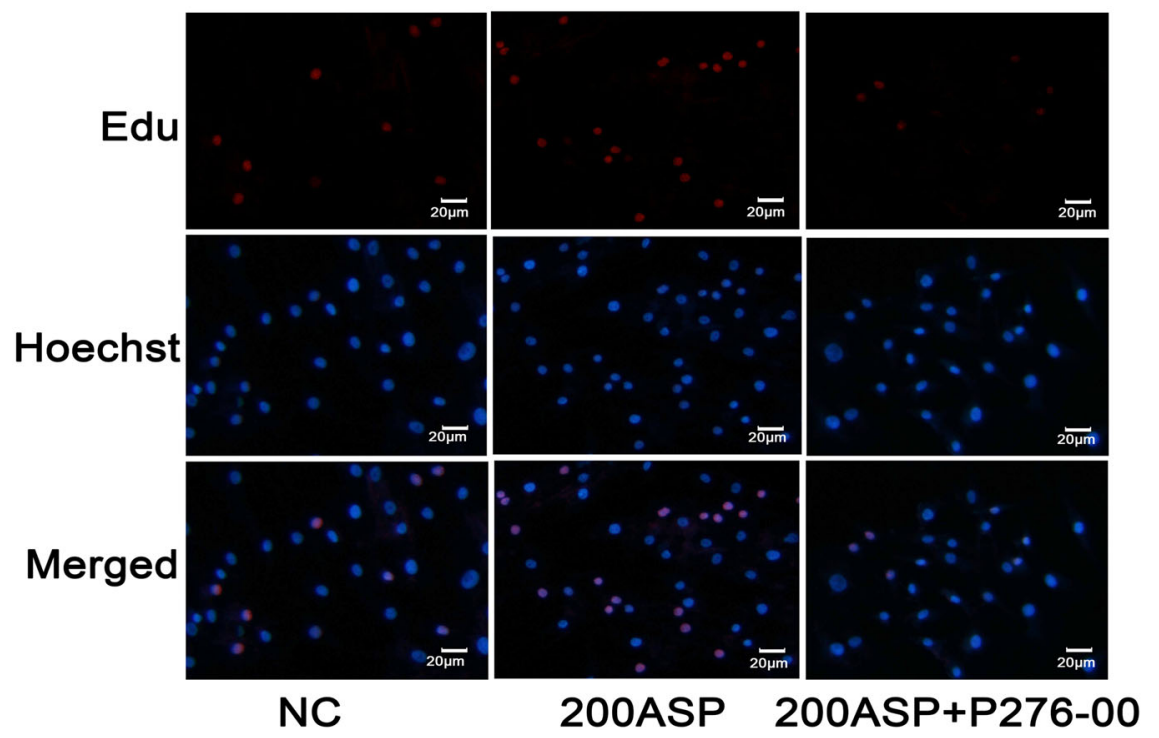

Fig. 2 ASP-induced chondrocyte proliferation. a Chondrocytes were treated with or without $200 \mu \mathrm{g} / \mathrm{ml}$ ASP for 6 days. The results are presented as the mean \pm SD of three independent experiments $(n=3)$. $\mathbf{b}$ Chondrocytes were collected after 4 days of exposure to $200 \mu \mathrm{g} / \mathrm{ml}$ ASP. Cyclin D1 and p21 were assessed by western blot (quantified in $\mathbf{c}$ and $\mathbf{d}$ ). e After treatment with the culture medium, $200 \mathrm{\mu g} / \mathrm{ml}$ ASP alone or cocultured with the indicated concentration of P276-00 $(2.5 \mu \mathrm{M}$ ) for 6 days. g Chondrocyte proliferation rate was detected by Edu assay at day 4 (quantified in $\mathbf{f}$. Data were presented as the mean \pm SD of three independent experiments $(n=3) .{ }^{*} p<0.05,{ }^{* *} p<0.01,{ }^{* * *} p<0.001,{ }^{*} p<0.0001$, and statistical significance was determined by Student's $t$ test

decreased Bcl-2 while increased Bax expression. On the contrary, ASP pretreatment significantly increased the expression of Bcl-2 while decreased the expression of Bax (Fig. 3e-g).
ASP protects chondrocytes from apoptosis by inducing autophagy

To determine whether the protective effect of ASP on chondrocytes was related to the autophagy activation, 
(a)
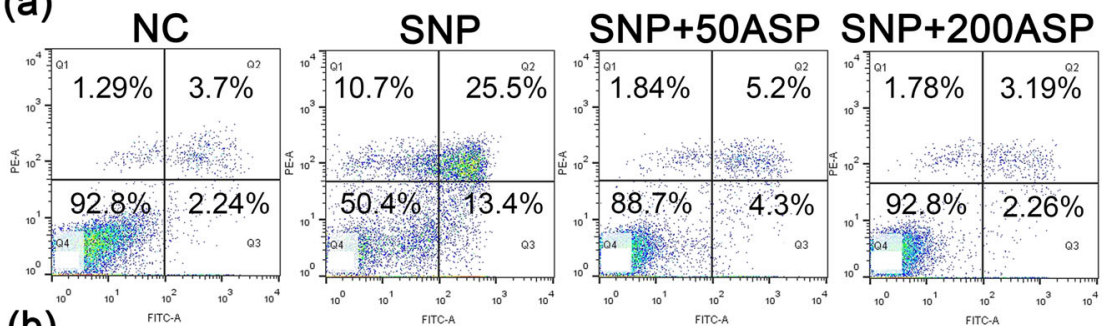

(b)

NC

SNP

SNP+50ASP SNP+200ASP

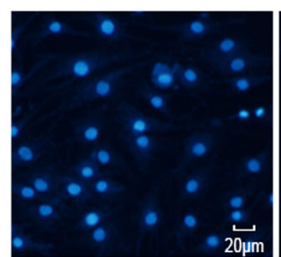

(c)

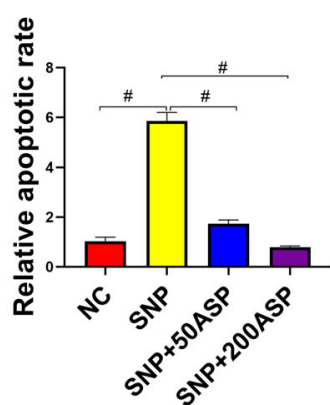

(f)
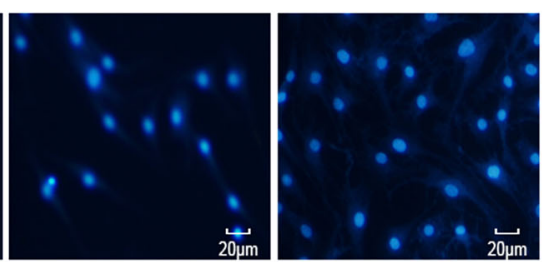

(d)

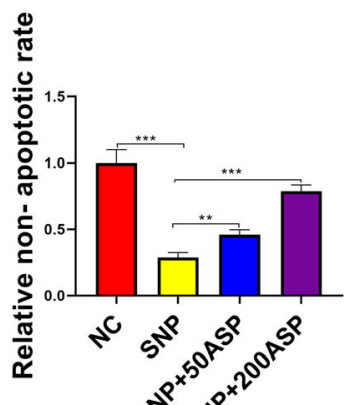

(g)

$$
\text { (e) }
$$
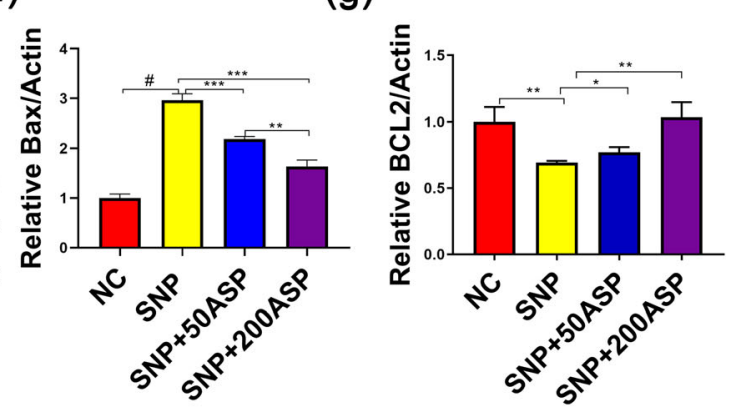

Fig. 3 The protective effect of ASP on chondrocyte apoptosis. Chondrocytes were pretreated with ASP for $4 \mathrm{~h}$ then stimulated with SNP (1 mg/ $\mathrm{ml}$ ) for $24 \mathrm{~h}$. a, b NC: chondrocytes were cultured in medium without AA for $24 \mathrm{~h}$. SNP: chondrocytes were treated with $1 \mathrm{mg} / \mathrm{ml} \mathrm{SNP}$ for $24 \mathrm{~h}$. SNP+50ASP/SNP+200ASP: chondrocytes were pretreated with different concentrations of ASP $(50 \mu \mathrm{g} / \mathrm{ml}, 00 \mu \mathrm{g} / \mathrm{ml})$ for $4 \mathrm{~h}$ then incubated with SNP for $24 \mathrm{~h}$. Chondrocyte apoptosis was detected by DAPI staining and flow cytometry assays (quantified in $\mathbf{c}$ and $\mathbf{d}$ ). e The level of Bcl2 and Bax was measured by western blot (quantified in $\mathbf{f}$ and $\mathbf{g}$ ). The results are presented as the means \pm SD of three independent experiments $(n=3)$. ${ }^{*} p<0.05,{ }^{* *} p<0.01,{ }^{* * *} p<0.001,{ }^{*} p<0.0001$, and statistical significance was determined by one-way ANOVA

autophagic protein levels such as microtubule-associated protein light chain 3B (LC3II/I), p62, Atg5, and Beclin-1 were evaluated by western blot. The results showed that SNP significantly decreased Beclin-1, Atg5, and LC3II expression $(p<0.05)$. On the contrary, when pretreated with ASP, increased LC3II, Beclin-1, and Atg5 levels were found in chondrocytes $(p<0.05)$. Moreover, the expression of LC3II, Atg5, and p62 was regulated in a dose-dependent manner (Fig. 4a-e). LC3II immunofluorescence staining aligned with western blot results (Fig. 4f). Furthermore, SNP increased the expression of p62, whereas decreased levels of p62 were observable after ASP treatment, indicating ASP increased autophagolysosomal degradation (Fig. 4a, c). Together, these data suggest ASP-induced autophagy rescued SNPinduced apoptosis in chondrocytes. 
(a)

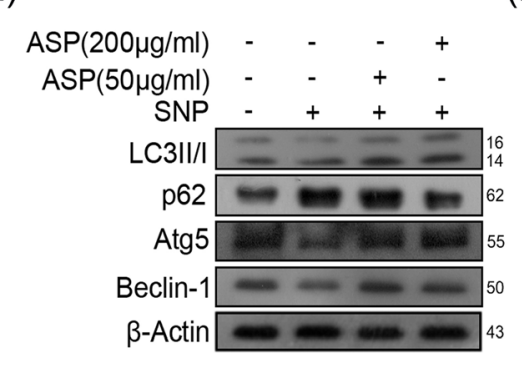

(c)

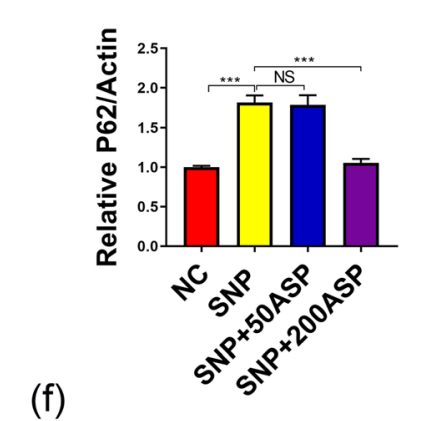

(d)
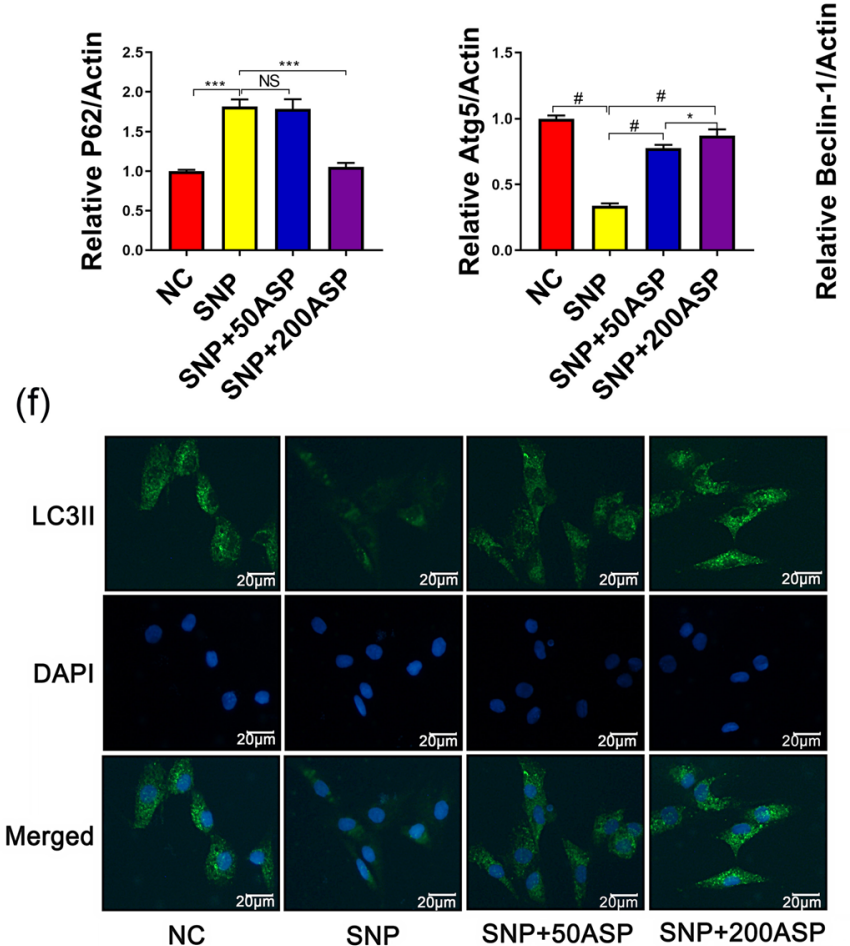

(b)

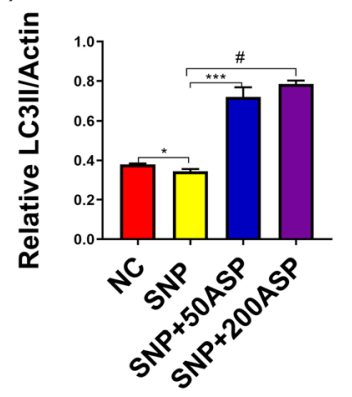

(e)
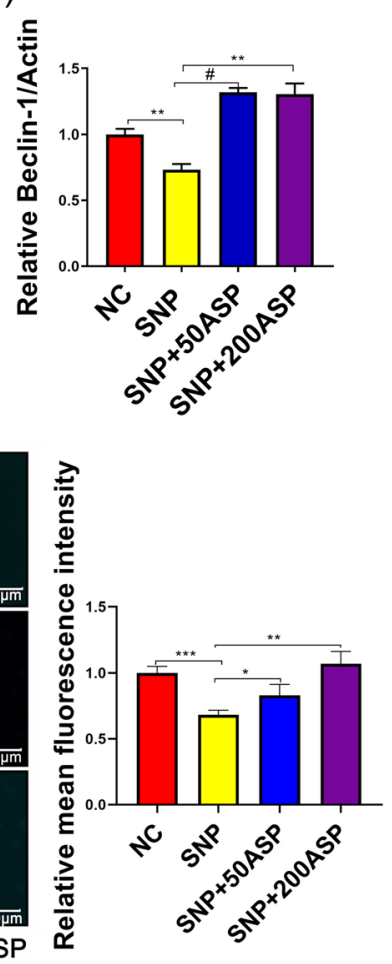

Fig. 4 ASP-induced autophagy in chondrocytes stimulated with SNP (1 mg/ml). a Autophagy-related proteins (LC3II/l, p62, Beclin-1, Atg5) were detected by western blot. $\mathbf{b}-\mathbf{e}$ The quantitative results are presented as the means $\pm \mathrm{SD}$ of three independent experiments ( $n=3$ ). $\mathbf{f} \mathrm{LC} 3-\|$ immunostaining. Significantly increased green bright puncta showed the formation of the autophagosomes. ${ }^{*} p<0.05,{ }^{* *} p<0.01,{ }^{* * *} p<0.001$, ${ }^{\#} p<0.0001$, and statistical significance was determined by one-way ANOVA

\section{ERK1/2 signaling pathway is activated in ASP-induced} autophagy

It is well reported that ERK1/2, one of the three main mitogen-activated protein kinase (MAPK) signaling pathways, regulates cell apoptosis and proliferation, and even affects autophagy. To illuminate the molecular mechanism of anti-apoptosis effect by ASP, we assessed the activation of the ERK1/2 signaling pathway in ASPstimulated chondrocytes. As shown in Fig. 5a-e, ASP significantly increased the expression of Ras, Raf, phosphorylated MEK1/2 (p-MEK1/2), and phosphorylated ERK1/2 (p-ERK1/2) ( $p<0.05)$, accompanied by increased expression of autophagy-related proteins LC3II and p62 degradation in SNP-treated cells, as shown in Fig. 6c-e. To further identify whether the ameliorated chondrocyte apoptosis was resulting from ASP-induced autophagy and ERK1/2 signal pathway activation, we used $20 \mu \mathrm{M}$ CQ (autophagy flux inhibitor), 3-MA (autophagy inhibitor), and SCH772984 (selective ERK1/2 inhibitor) to pretreat chondrocytes. Flow cytometry results showed that the protective effect of ASP on chondrocyte apoptosis was significantly inhibited by 3-MA and SCH772984 treatment (Fig. 6a). In addition, ASP significantly increased bright LC3II puncta compared with the SNP group, while bright LC3II puncta were decreased by the inhibition of the ERK1/2 pathway and 3- 
(a)

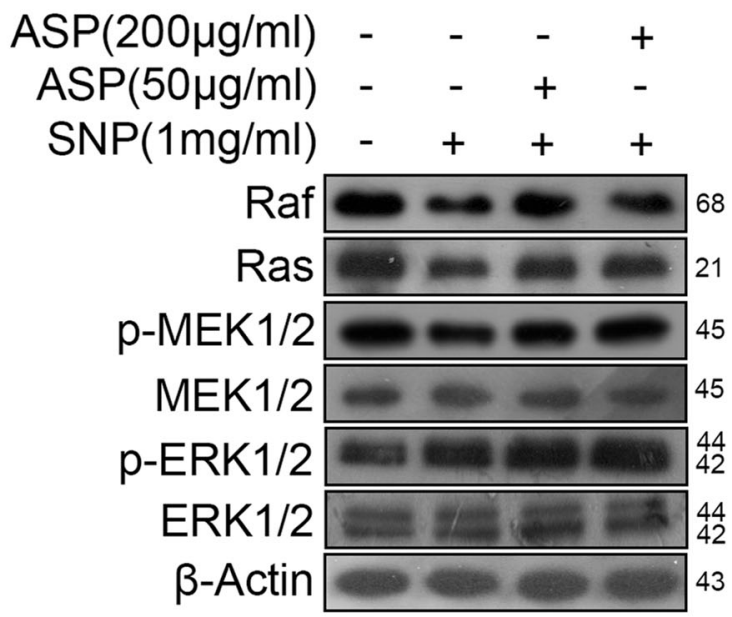

(c)

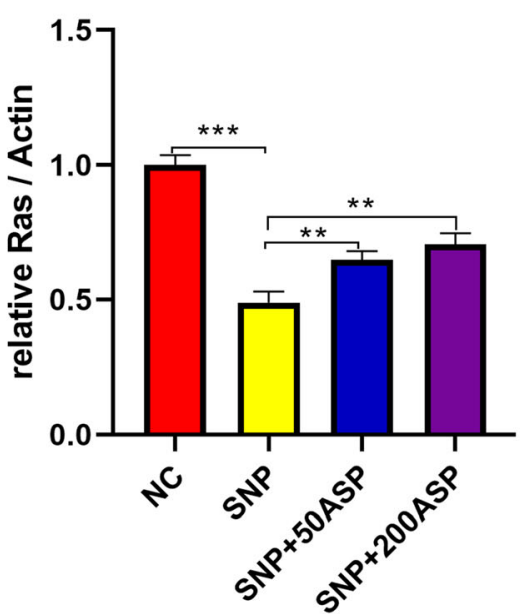

(d)

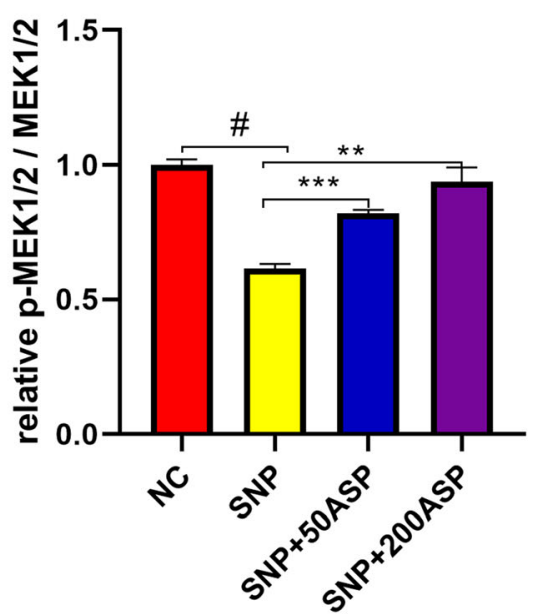

(b)
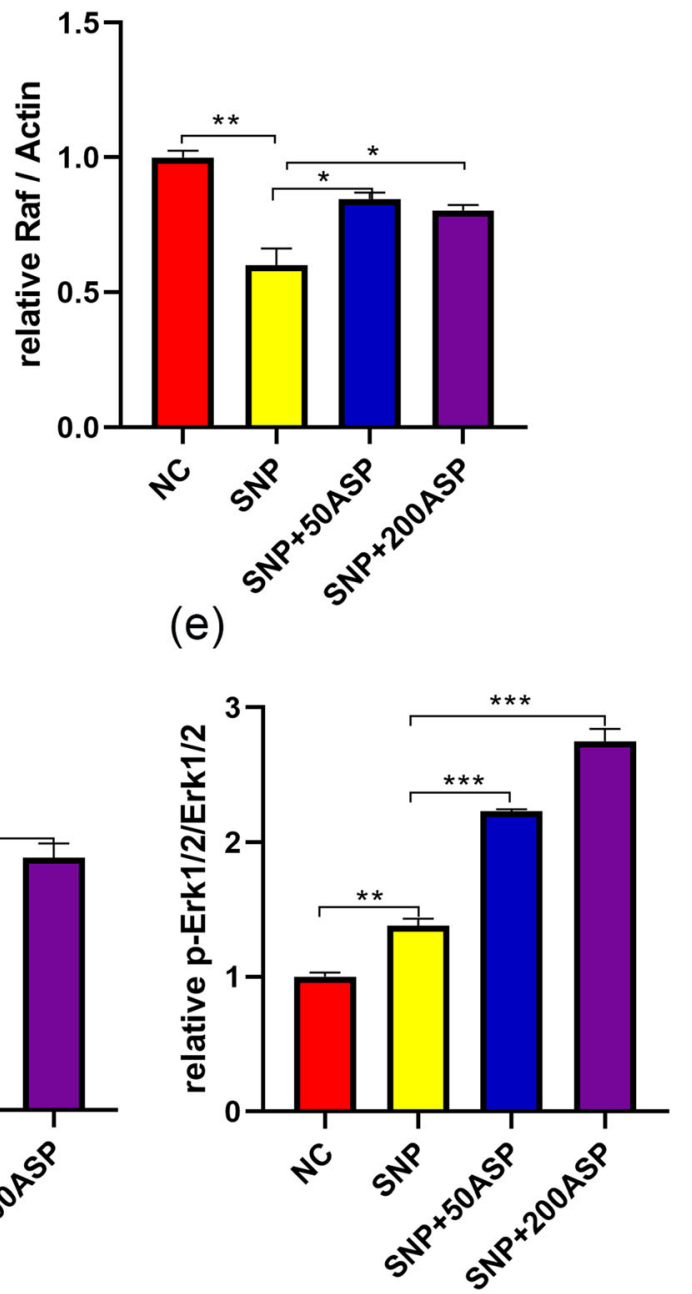

Fig. 5 ASP activated the ERK1/2 signaling pathway in chondrocytes stimulated with SNP. Chondrocytes were pretreated with ASP for $4 \mathrm{~h}$ then stimulated with SNP (1 mg/ml) for 24 h. a, b. The level of Raf, Ras, p-MEK1/2, and p-ERK1/2 in chondrocytes after stimulation were measured by western blot. b-e. Quantitative analysis of Raf, Ras, p-MEK1/2, and p-ERK1/2 levels. The data are presented as the mean \pm SD of three independent experiments $(n=3)$. ${ }^{*} p<0.05$, ${ }^{* *} p<0.01,{ }^{* *} p<0.001,{ }^{*} p<0.0001$, and statistical significance was determined by one-way ANOVA

MA treatment (Fig. 6b). To further evaluate the effect of ASP on autophagy flux, we used mRFP-GFP-LC3 autophagic puncta to visualize the level of autophagy. Enhanced autophagy was observed in the ASP-treated group whereas inhibited autophagy was detected with the ERK1/2 pathway inhibition (Fig. 6f). All these results suggested that ASP-mediated autophagy levels are linked to the ERK1/2 signaling pathway in SNP-stimulated chondrocytes.

\section{Discussion}

In this study, we first demonstrated that ASP protects chondrocytes from SNP-induced apoptosis through the activation of autophagy. It has been reported that levels of nitrite, a stable end product of nitric oxide (NO) metabolism, are elevated in serum and synovial fluid samples of OA [22]. In addition, synovial cells and cartilage cells in OA produced large amounts of NO [23]. The negative effects of $\mathrm{NO}$ include enhancement of matrix metalloproteinase activity, a reduction in interleukin-1 receptor antagonist synthesis, and the promotion of apoptosis, which are closely associated with the occurrence and development of OA [24-26]. Thus, we chose SNP to induce NO-related apoptosis and discovered that chondrocyte viability declined in a time- and dosedependent manner. 
(a)

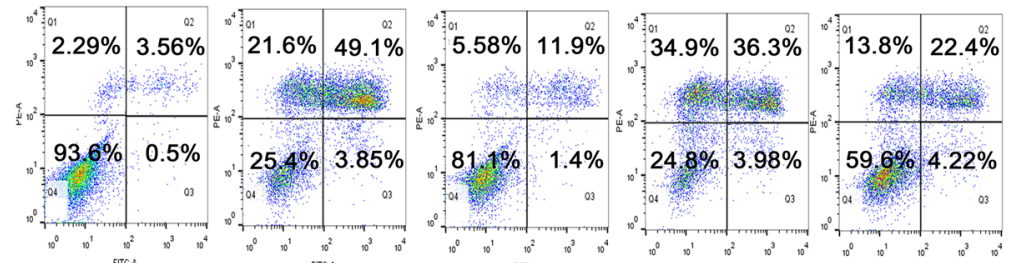

(b)
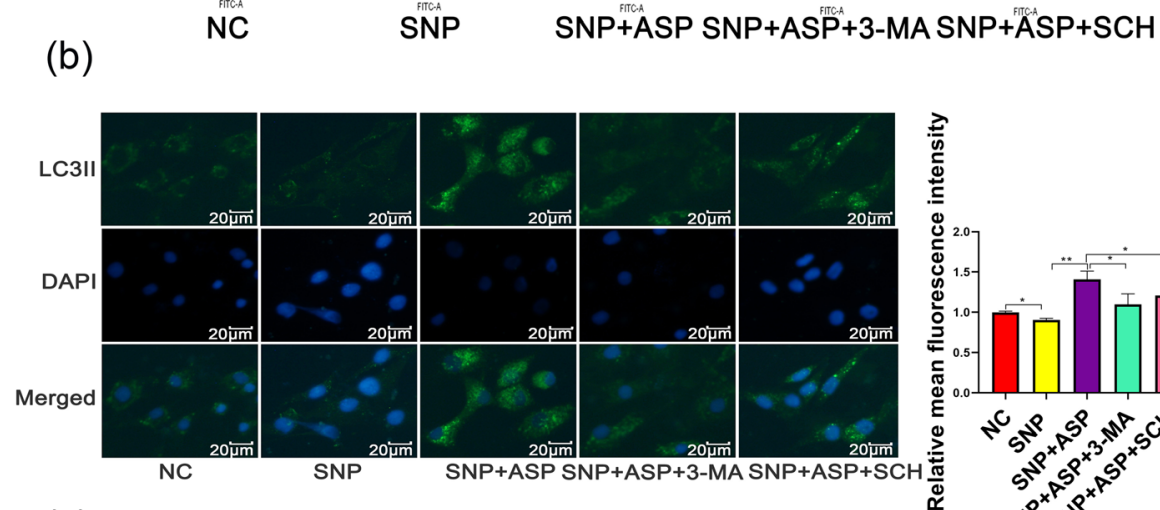

(c)

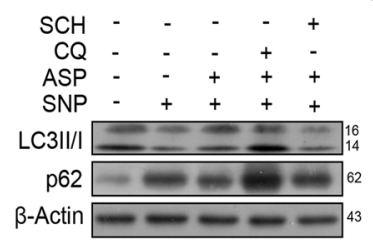

(f)

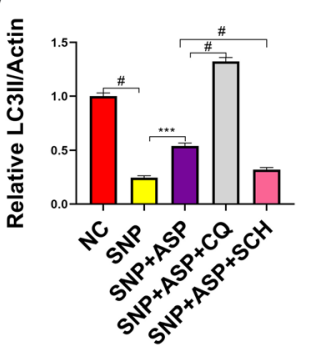

(e)
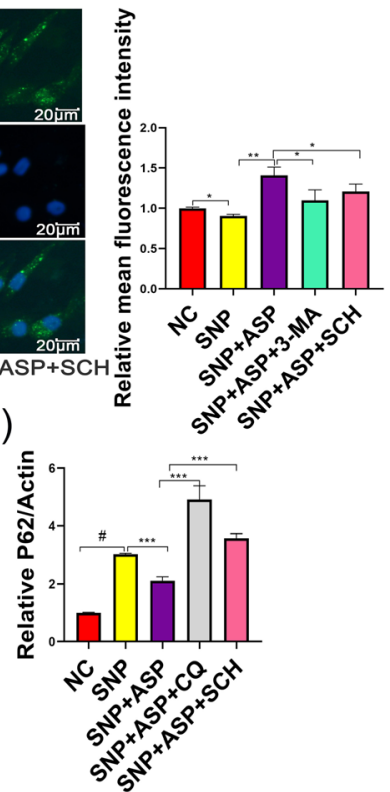
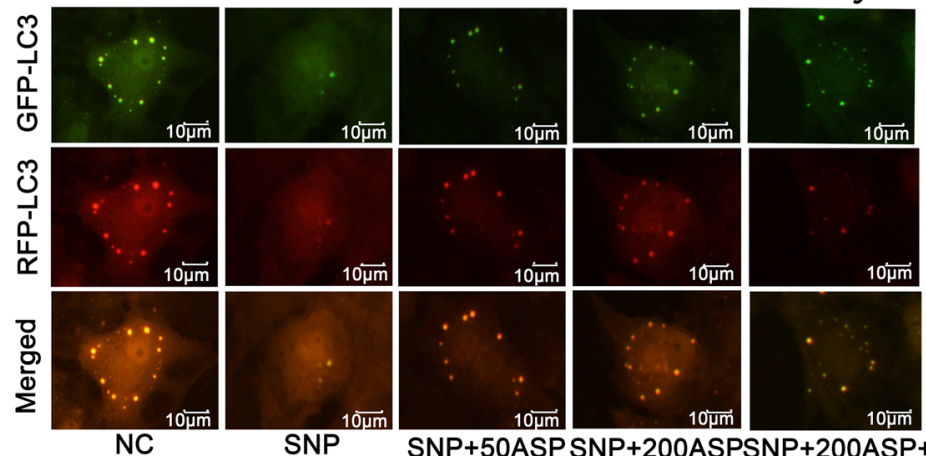

SNP

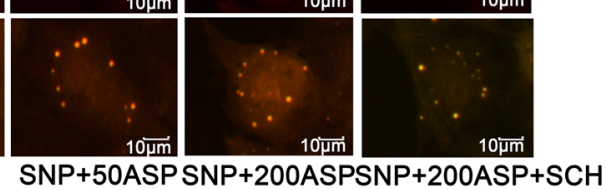

Fig. 6 ASP diminished chondrocyte apoptosis via activation of autophagy. Chondrocytes were pretreated with 3-MA (10 $\mu \mathrm{M}), C Q(20 \mu \mathrm{M})$, and SCH772984 (10 nM) for $4 \mathrm{~h}$ before ASP treatment followed by SNP $(1 \mathrm{mg} / \mathrm{ml})$ for $24 \mathrm{~h}$. a Chondrocyte apoptosis was measured by flow cytometry. b The formation of autophagosome was detected by LC3II immunostaining. c Levels of LC3II/I and p62 in chondrocytes after stimulation were measured by western blot. d Quantitative analysis of LC3II in chondrocytes. e Quantitative analysis of p62 in chondrocytes. f Representative microscopy images of tfLC3 puncta in chondrocytes stained for autophagosomes (green) and autolysosomes (red) as an indicator of autophagy flux. Autophagy increased in the ASP-treated groups in a dose-dependent manner. The data are presented as the mean \pm SD of three independent experiments $(n=3)$. ${ }^{* *} p<0.001,{ }^{\#} p<0.0001$, and statistical significance was determined by one-way ANOVA

p53, which targets p21, can inhibit cell growth by blocking the cell cycle and induction of cell cycle arrest in the G0-G1 phase when the p53-p21 signaling pathway is activated [27]. One study has reported the role of p21 in potentiating cancer stem cells (CSC) via the activation of canonical Wnt signaling due to TCF1/Cyclin D1 upregulation. This results in the promotion of self-renewal and leads to the proliferation of CSC/progenitor cells that fuels tumor growth and metastasis [28]. Our study showed that ASP promotes chondrocyte 
proliferation via downregulation of $\mathrm{p} 21$ and upregulation of CyclinD1 expression, which were consistent with previous studies (Fig. 2).

Since SNP has been reported to induce mitochondrial apoptosis [29], alterations in mitochondrial membrane potential, and associated gene and protein expression levels, were investigated. Decreased mitochondrial membrane potential leads to increased membrane permeability, and mitochondrial membrane permeability may be regulated by the Bcl-2 family [30]. Conversely, the Bax protein increases the permeability of the mitochondrial membrane by forming activated oligomers, promoting Cyt- $C$ release, and ultimately inducing apoptosis [31]. In our study, increased Bax expression and decreased Bcl-2 are involved in SNP-induced apoptosis, which was consistent with previous studies (Fig. 3).

Cetrullo et al. [32] demonstrated that oxidative stress inhibits the expression of autophagy-related proteins in chondrocytes and promotes apoptosis. Previous studies have shown OA cartilage produces a larger amount of NO compared with normal cartilage [33]. In addition, NO suppresses cartilage matrix synthesis and enhances degradation [34, 35]. Consequently, accumulating evidences showed that antioxidants, like $\mathrm{N}$-acetyl cysteine (NAC) and eicosapentaenoic acid (EPA), can attenuate chondrocyte apoptosis caused by radical oxygen (ROS) and nitrogen (RNS) species in OA or after traumatic cartilage injury [36, 37]. Additionally, oxidative stress can lead to mitochondrial dysfunction, mitochondrial DNA damage, telomere instability, cell senescence, and anabolic dysfunction $[38,39]$. As a result, more and more researchers are focusing on the therapeutic effect of antioxidants on OA. Polyphenols, like carnosol, hydroxytyrosol, curcumin, and genistein, have been revealed to have therapeutic potential in arthritis with regard to their antioxidant and anti-inflammatory features [40]. Another extensively investigated antioxidant is melatonin. It is reported to play a protective role in OA due to its ability to regulate apoptosis, ER stress, and mitochondrial activity [41].

Our study suggested that SNP, an oxidative stress inducer, inhibits autophagy levels, which was confirmed by Atg5, Beclin-1, LC3I/II, and p62 expression. LC3, an important constituent of autophagosomes, also plays an essential role in the fusion of autophagosomes with lysosomes for the degradation of damaged organelles by lysosomal enzymes [16]. LC3II has the ability to determine the membrane curvature, thus has a role in regulating the size of the autophagosome [42]. The expression level of LC3II could be affected both genetically by autophagy-related genes like Beclin-1 and SQSM T1/p62 or chemically by 3-MA and CQ [43-46]. Beclin1 allows nucleation of the autophagosome and the conversion of LC3B-I to LC3B-II through lipidation by an ubiquitin-like system to form the autophagosome [43]. SQSMT1/p62 has a receptor function to recognize ubiquitinated proteins that need to be removed from the cytoplasm during autophagy; its amount is generally considered to inversely correlate with autophagic activity [44]. 3-MA inhibits autophagy by blocking autophagosome formation via the inhibition of class III PI3K, whereas CQ block the autophagic flux by decreasing the fusion process of autophagosome and lysosome [45, 46]. In our study, we first demonstrated ASP increased autophagy-related protein LC3II, Atg5, and Beclin-1 expression, indicating ASP promoted autophagy of chondrocyte. Additionally, we also detected the expression of p62, an autophagy substrate known to recruit ubiquitinated proteins and gets degraded as autophagic flux progress. The results suggest that ASP decreases p62 accumulation induced by SNP and CQ treatment further enhances p62 expression, indicating ASP not only enhanced the LC3II expression but also activated the autophagic flux. To further explore the correlation between ASP-induced autophagy and SNPinduced apoptosis, we used 3-MA as an autophagy inhibitor to block autophagy initiation. The results suggested that the protective effect of ASP against SNPinduced apoptosis was partly inhibited. All these findings confirm that ASP-induced autophagy plays an important role in preventing SNP-induced apoptosis in chondrocytes.

Autophagy is regulated by multiple signaling pathways in chondrocytes. Inhibition of the NF- $\mathrm{KB}$ pathway promotes the expression of Atg5, Atg7, and LC3II and activates autophagy [47]. Shi et al. showed that autophagy levels were significantly inhibited after activation of the p38 signaling pathway in osteoarthritis [48]. In addition, $\mathrm{Li}$ et al. reported that the ERK1/2 signaling pathway activation was involved in chondrocyte autophagy, which protected chondrocyte from apoptosis [49]. Moreover, pathways such as AMPK/mTOR [50], PI3K/AKT [51], and AKT/mTOR [52] were associated with autophagy in chondrocytes. We found that ASP-induced autophagy plays a critical role in the prevention of SNP-induced apoptosis via the ERK1/2 signaling pathway (Fig. 5). In keeping with the previous results, we discovered that ASP induced increased expression of p-ERK1/2 accompanying with a high expression of LC3II in chondrocytes treated with SNP and downregulated the expression of p62 simultaneously. For further proof, the application of SCH772984, an inhibitor of ERK1/2, significantly blocked the ASP-induced autophagy as it decreased the expression of LC3II and restored the SNP-induced expression of p62. Taken together, our results clearly demonstrated that the modulation of ERK1/2 plays a key role in the regulation of autophagy in chondrocytes treated with ASP and SNP. 
Nonetheless, there are two major limitations in this study that could be addressed in future research. First, this study was based on the primary cultured chondrocytes which were thought to lose their characteristic in vivo in the synovium niche. The reality of chondrocyte apoptosis due to OA progression would be more complicated. Secondly, besides oral intake of ASP, whether there are more efficient ways to treat OA with ASP still needs to be looked into.

\section{Conclusion}

ASP decreases SNP-induced cartilage damage and enhances chondrocyte proliferation in a CyclinD1- and p21-dependent manner. Besides, ASP activates autophagy to protect chondrocytes from apoptosis, via the ERK1/2 signal pathway. In addition, inhibitors of autophagy and the ERK1/2 pathway significantly abolishes the anti-apoptotic function of ASP against SNP. These findings indicate that ASP might be a promising natural compound for the treatment of OA.

\section{Supplementary Information}

The online version contains supplementary material available at https://doi. org/10.1186/s13075-020-02409-3.

Additional file 1: SNP viability.

\section{Abbreviations}

OA: Osteoarthritis; ASP: Angelica sinensis polysaccharide; SNP: Sodium nitroprusside; NO: Nitric oxide; AA: Ascorbic acid; LC3: Microtubule-associated protein 1 light chain 3; SQSTM1/p62: Sequestosome 1; Beclin-1: Autophagyregulated protein; ERK1/2: Extracellular signal-regulated kinase1/2; SCH772984: Inhibitor of the ERK1/2 signal pathway;

RIPA: Radioimmunoprecipitation assay buffer; DMEM: Dulbecco's modified Eagle's medium; PVDF: Polyvinylidene fluoride; CSC: Cancer stem cells; CyclinD1: Cell cycle regulatory proteins D1; MAPK: Mitogen-activated protein kinase; Raf: Raf kinase, effector of Ras; Cyt-c: Cytochrome c oxidase;

Atg5: Autophagy-related 5; Atg7: Autophagy-related 7; Bax: BCL2-associated $X$ protein; $\mathrm{BCl}-2$ : $\mathrm{BCL} 2$ apoptosis regulator; 3-MA: 3-Methyladenine;

CQ: Chloroquine; mTOR: Mechanistic target of rapamycin kinase; AKT: Serine/ threonine kinase

\section{Acknowledgements}

We want to thank all the patients who participated in our study and professor Dawei Li for giving suggestions. We are also thankful for the support of phase V 333 Project training funds of Jiangsu Province.

\section{Authors' contributions}

Yuji Wang and Andre J. Van Wijnen contributed to the conception and design of the study. Chao Xu and Su Ni performed the main experiments. Shijie Jiang, Chao Zhuang, and Ruixia Zhu contributed to the drafting of the article. Gongyin Zhao completed the acquisition or preparation of the clinical samples. Chao Xu, Su Ni, Chenkai Li, and Liangliang Wang contributed to the analysis and interpretation of the data. Yuji Wang contributed to the critical revision and provided important intellectual feedbacks. All the authors read and approved the final manuscript.

\section{Funding}

This work was supported by grants from the National Natural Science Foundation of China (81171680 to Y.W.), the project of Jiangsu province (BE2015632 to Y.W.), the Natural Science Foundation of the Jiangsu for Youth (BK20180182 to S.N.), the Changzhou Science and Technology Program
(CJ20180057 to S.N; QN201930 to C.L.), and the China Postdoctoral Science Foundation (2019M651898 to S.N.).

\section{Availability of data and materials}

The datasets used in the present study are available from the corresponding authors on reasonable request.

\section{Ethics approval and consent to participate}

All participants had signed a written informed consent prior to the subjects entering the study. The study was approved by the Nanjing Medical University Review Board, and the file number is [2017] KY035-01.

\section{Consent for publication}

Not applicable.

\section{Competing interests}

The authors declare no conflict of interest.

\section{Author details}

'Trauma Center, The Affiliated Changzhou No.2 People's Hospital of Nanjing Medical University, 29 Xinglong Alley, Changzhou 213003, China. ${ }^{2}$ Medical Research Center, The Affiliated Changzhou No.2 People's Hospital of Nanjing Medical University, 29 Xinglong Alley, Changzhou 213003, China. ${ }^{3}$ Department of Orthopedics, The Affiliated Changzhou No.2 People's Hospital of Nanjing Medical University, 29 Xinglong Alley, Changzhou 213003, China. ${ }^{4}$ Department of Orthopedic Surgery and Biochemistry \& Molecular Biology, Mayo Clinic, Rochester, MN, USA. ${ }^{5}$ Department of Orthopedics, The Third Affiliated Hospital of Gansu University of Chinese Medicine, 222 Silong Road, Baiyin 730900, China.

Received: 14 May 2020 Accepted: 26 December 2020

Published online: 30 January 2021

\section{References}

1. Dieppe PA, Lohmander LS. Pathogenesis and management of pain in osteoarthritis. Lancet. 2005;365(9463):965-73.

2. Blanco FJ, Rego I, Ruiz-Romero C. The role of mitochondria in osteoarthritis. Nat Rev Rheumatol. 2011;7(3):161-9.

3. Eskelinen EL. Maturation of autophagic vacuoles in mammalian cells. Autophagy. 2005;1(1):1-10.

4. Starkman BG, Cravero JD, Delcarlo M, Loeser RF. IGF-I stimulation of proteoglycan synthesis by chondrocytes requires activation of the PI 3kinase pathway but not ERK MAPK. Biochem J. 2005;389(Pt 3):723-9.

5. Hwang HS, Kim HA. Chondrocyte apoptosis in the pathogenesis of osteoarthritis. Int J Mol Sci. 2015:16(11):26035-54.

6. Zhang N, Diao Y, Hua R, Wang J, Han S, Li J, Yin Y. Nitric oxide-mediated pathways and its role in the degenerative diseases. Front Biosci (Landmark Ed). 2017;22:824-34.

7. Wang Q, Ding F, Zhu N, He P, Fang Y. Determination of the compositions of polysaccharides from Chinese herbs by capillary zone electrophoresis with amperometric detection. Biomed Chromatogr. 2003;17(7):483-8.

8. Sun Y, Tang J, Gu X, Li D. Water-soluble polysaccharides from Angelica sinensis (Oliv.) Diels: preparation, characterization and bioactivity. Int J Biol Macromol. 2005;36(5):283-9.

9. Carlo MD Jr, Loeser RF. Increased oxidative stress with aging reduces chondrocyte survival: correlation with intracellular glutathione levels. Arthritis Rheum. 2003:48(12):3419-30.

10. Cho CH, Mei QB, Shang P, Lee SS, So HL, Guo X, Li Y. Study of the gastrointestinal protective effects of polysaccharides from Angelica sinensis in rats. Planta Med. 2000;66(4):348-51.

11. Shang $P$, Qian AR, Yang TH, Jia M, Mei QB, Cho CH, Zhao WM, Chen ZN. Experimental study of anti-tumor effects of polysaccharides from Angelica sinensis. World J Gastroenterol. 2003;9(9):1963-7.

12. Ooi VE, Liu F. Immunomodulation and anti-cancer activity of polysaccharide-protein complexes. Curr Med Chem. 2000;7(7):715-29.

13. Xie Y, Zhang H, Zhang Y, Wang C, Duan D, Wang Z. Chinese Angelica polysaccharide (CAP) alleviates LPS-induced inflammation and apoptosis by down-regulating COX-1 in PC12 cells. Cell Physiol Biochem. 2018;49(4): 1380-8. 
14. Zhuang C, Xu NW, Gao GM, Ni S, Miao KS, Li CK, Wang LM, Xie HG. Polysaccharide from Angelica sinensis protects chondrocytes from $\mathrm{H}_{2} \mathrm{O}_{2}$ induced apoptosis through its antioxidant effects in vitro. Int J Biol Macromol. 2016:87:322-8.

15. Musumeci G, Castrogiovanni P, Trovato FM, Weinberg AM, AI-Wasiyah MK, Alqahtani MH, Mobasheri A. Biomarkers of chondrocyte apoptosis and autophagy in osteoarthritis. Int J Mol Sci. 2015;16(9):20560-75.

16. Gordy C, He YW. The crosstalk between autophagy and apoptosis: where does this lead? Protein Cell. 2012;3(1):17-27.

17. Wang P, Dong R, Wang B, Lou Z, Ying J, Xia C, Hu S, Wang W, Sun Q, Zhang $P$, et al. Genome-wide microRNA screening reveals miR-582-5p as a mesenchymal stem cell-specific microRNA in subchondral bone of the human knee joint. J Cell Physiol. 2019;234(12):21877-88.

18. Denton D, Kumar S. Autophagy-dependent cell death. Cell Death Differ. 2019;26(4):605-16

19. Boya P, González-Polo R-A, Casares N, Perfettini J-L, Dessen P, Larochette N, Métivier D, Meley D, Souquere S, Yoshimori T, et al. Inhibition of macroautophagy triggers apoptosis. Mol Cell Biol. 2005;25(3):1025-40.

20. Maiuri MC, Zalckvar E, Kimchi A, Kroemer G. Self-eating and self-killing: crosstalk between autophagy and apoptosis. Nat Rev Mol Cell Biol. 2007; 8(9):741-52

21. Shakibaei M, Mobasheri A, Buhrmann C. Curcumin synergizes with resveratrol to stimulate the MAPK signaling pathway in human articular chondrocytes in vitro. Genes Nutr. 2011;6(2):171-9.

22. Hashimoto S, Takahashi K, Amiel D, Coutts RD, Lotz M. Chondrocyte apoptosis and nitric oxide production during experimentally induced osteoarthritis. Arthritis Rheum. 1998;41(7):1266-74.

23. Abramson SB. Nitric oxide in inflammation and pain associated with osteoarthritis. Arthritis Res Ther. 2008;10(Suppl 2):S2.

24. Fei J, Liang B, Jiang C, Ni H, Wang L. Luteolin inhibits IL-1beta-induced inflammation in rat chondrocytes and attenuates osteoarthritis progression in a rat model. Biomed Pharmacother. 2019;109:1586-92.

25. Tonomura H, Takahashi KA, Mazda O, Arai Y, Inoue A, Terauchi R, Shin-Ya M, Kishida T, Imanishi J, Kubo T. Glutamine protects articular chondrocytes from heat stress and NO-induced apoptosis with HSP70 expression. Osteoarthr Cartil. 2006;14(6):545-53.

26. Madzuki IN, Lau SF, Abdullah R, Mohd Ishak NI, Mohamed S. Vernonia amygdalina inhibited osteoarthritis development by anti-inflammatory and anticollagenase pathways in cartilage explant and osteoarthritis-induced rat model. Phytother Res. 2019;33(7):1784-93.

27. Eckner R. p53-dependent growth arrest and induction of p21: a critical role for PCAF-mediated histone acetylation. Cell Cycle. 2012;11(14):2591-2.

28. Benard O, Qian X, Liang H, Ren Z, Suyama K, Norton L, Hazan RB. p21CIP1 Promotes Mammary Cancer-Initiating Cells via Activation of Wnt/TCF1/ CyclinD1 Signaling. Mol Cancer Res 2019;17(7):1571-81.

29. Liu X, Guo P, Liu A, Wu Q, Xue X, Dai M, Hao H, Qu W, Xie S, Wang X, et al. Nitric oxide (NO)-mediated mitochondrial damage plays a critical role in T-2 toxin-induced apoptosis and growth hormone deficiency in rat anterior pituitary GH3 cells. Food Chem Toxicol. 2017;102:11-23.

30. Robertson JD, Zhivotovsky B, Gogvadze V, Orrenius S. Outer mitochondrial membrane permeabilization: an open-and-shut case? Cell Death Differ. 2003;10(5):485-7.

31. Westphal D, Kluck RM, Dewson G. Building blocks of the apoptotic pore: how Bax and Bak are activated and oligomerize during apoptosis. Cell Death Differ. 2014:21(2):196-205.

32. Cetrullo S, D'Adamo S, Guidotti S, Borzi RM, Flamigni F. Hydroxytyrosol prevents chondrocyte death under oxidative stress by inducing autophagy through sirtuin 1-dependent and -independent mechanisms. Biochim Biophys Acta. 2016;1860(6):1181-91.

33. Zhuang C, Wang Y, Zhang Y, Xu N. Oxidative stress in osteoarthritis and antioxidant effect of polysaccharide from Angelica sinensis. Int J Biol Macromol. 2018;115:281-6.

34. Pelletier JP, Mineau F, Ranger P, Tardif G, Martel-Pelletier J. The increased synthesis of inducible nitric oxide inhibits IL-1ra synthesis by human articular chondrocytes: possible role in osteoarthritic cartilage degradation. Osteoarthr Cartil. 1996:4(1):77-84.

35. Wang W, Wei S, Luo M, Yu B, Cao J, Yang Z, Wang Z, Goldring MB, Chen J. Oxidative stress and status of antioxidant enzymes in children with KashinBeck disease. Osteoarthr Cartil. 2013;21(11):1781-9.

36. Riegger J, Joos H, Palm HG, Friemert B, Reichel H, Ignatius A, Brenner RE. Antioxidative therapy in an ex vivo human cartilage trauma-model: attenuation of trauma-induced cell loss and ECM-destructive enzymes by $\mathrm{N}$ acetyl cysteine. Osteoarthr Cartil. 2016;24(12):2171-80.

37. Sakata S, Hayashi S, Fujishiro T, Kawakita K, Kanzaki N, Hashimoto S, Iwasa K, Chinzei N, Kihara S, Haneda M, et al. Oxidative stress-induced apoptosis and matrix loss of chondrocytes is inhibited by eicosapentaenoic acid. J Orthop Res. 2015;33(3):359-65.

38. Finkel T, Holbrook NJ. Oxidants, oxidative stress and the biology of ageing Nature. 2000:408(6809):239-47.

39. Maneiro E, Lopez-Armada MJ, de Andres MC, Carames B, Martin MA, Bonilla A, Del Hoyo P, Galdo F, Arenas J, Blanco FJ. Effect of nitric oxide on mitochondrial respiratory activity of human articular chondrocytes. Ann Rheum Dis. 2005;64(3):388-95.

40. Oliviero F, Scanu A, Zamudio-Cuevas Y, Punzi L, Spinella P. Anti-inflammatory effects of polyphenols in arthritis. J Sci Food Agric. 2018;98(5):1653-9.

41. Hosseinzadeh A, Kamrava SK, Joghataei MT, Darabi R, Shakeri-Zadeh A, Shahriari M, Reiter RJ, Ghaznavi H, Mehrzadi S. Apoptosis signaling pathways in osteoarthritis and possible protective role of melatonin. J Pineal Res. 2016;61(4):411-25.

42. Jiang $\mathrm{S}$, Chang H, Deng S, Fan D. Icariin enhances the chemosensitivity of cisplatinresistant ovarian cancer cells by suppressing autophagy via activation of the AKT/mTOR/ATG5 pathway. Int J Oncol. 2019;54(6):1933-42.

43. Hill SM, Wrobel L, Rubinsztein DC. Correction to: Post-translational modifications of Beclin 1 provide multiple strategies for autophagy regulation. Cell Death Differ. 2019;26(12):2810.

44. Komatsu M, Ichimura Y. Physiological significance of selective degradation of p62 by autophagy. FEBS Lett. 2010;584(7):1374-8.

45. Mauthe M, Orhon I, Rocchi C, Zhou X, Luhr M, Hijlkema KJ, Coppes RP, Engedal N, Mari M, Reggiori F. Chloroquine inhibits autophagic flux by decreasing autophagosome-lysosome fusion. Autophagy. 2018;14(8):1435-55.

46. Wu YT, Tan HL, Shui G, Bauvy C, Huang Q, Wenk MR, Ong CN, Codogno P, Shen HM. Dual role of 3-methyladenine in modulation of autophagy via different temporal patterns of inhibition on class I and III phosphoinositide 3-kinase. J Biol Chem. 2010;285(14):10850-61.

47. Mi B, Wang J, Liu Y, Liu J, Hu L, Panayi AC, Liu G, Zhou W. Icariin activates autophagy via down-regulation of the NF-kappaB signaling-mediated apoptosis in chondrocytes. Front Pharmacol. 2018;9:605.

48. Shi J, Zhang C, Yi Z, Lan C. Explore the variation of MMP3, JNK, p38 MAPKs, and autophagy at the early stage of osteoarthritis. IUBMB Life. 2016;68(4):293-302.

49. Li X, Feng K, Li J, Yu D, Fan Q, Tang T, Yao X, Wang X. Curcumin Inhibits Apoptosis of Chondrocytes through Activation ERK1/2 Signaling Pathways Induced Autophagy. Nutrients. 2017;21;9(4):414.

50. Zhao X, Li Y, Lin X, Wang J, Zhao X, Xie J, Sun T, Fu Z. Ozone induces autophagy in rat chondrocytes stimulated with IL-1beta through the AMPK mTOR signaling pathway. J Pain Res. 2018;11:3003-17.

51. Sun W, Li Y, Wei S. miR-4262 regulates chondrocyte viability, apoptosis, autophagy by targeting SIRT1 and activating PI3K/AKT/mTOR signaling pathway in rats with osteoarthritis. Exp Ther Med. 2018;15(1):1119-28.

52. Wang ZJ, Zhang HB, Chen $\mathrm{C}$, Huang $\mathrm{H}$, Liang JX. Effect of PPARG on AGEsinduced AKT/MTOR signaling-associated human chondrocytes autophagy. Cell Biol Int. 2018;42(7):841-8.

\section{Publisher's Note}

Springer Nature remains neutral with regard to jurisdictional claims in published maps and institutional affiliations.

Ready to submit your research? Choose BMC and benefit from:

- fast, convenient online submission

- thorough peer review by experienced researchers in your field

- rapid publication on acceptance

- support for research data, including large and complex data types

- gold Open Access which fosters wider collaboration and increased citations

- maximum visibility for your research: over $100 \mathrm{M}$ website views per year

At $\mathrm{BMC}$, research is always in progress.

Learn more biomedcentral.com/submissions 